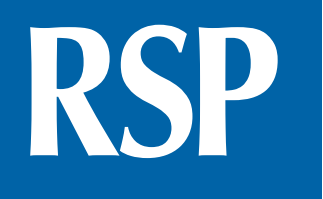

http://www.rsp.fsp.usp.br/

Revista de

Saúde Pública

\title{
Development and evaluation of food environment audit instrument: AUDITNOVA
}

\author{
Camila Aparecida Borges' (iD, Patricia Constante Jaime ${ }^{\mathrm{l}}$ \\ I Universidade de São Paulo. Faculdade de Saúde Pública. Departamento de Nutrição. São Paulo, SP, Brasil
}

\begin{abstract}
OBJECTIVE: To develop and assess the reliability of an instrument that enables auditing information on consumer food environment indicators, such as availability, price, promotional and advertising strategies, and quantity of brands available, using the food recommendations adopted by the Dietary Guidelines for the Brazilian Population as a theoretical basis.
\end{abstract}

METHODS: This is a methodological study in two phases: 1. development of the audit instrument and 2. assessment of its reliability and reproducibility. The Content Validity Index was estimated for each instrument item ( $>0.80$ satisfactory). Inter-rater and test-retest reliability were assessed by percentage agreement and Kappa coefficients. Pearson's correlation coefficient and Scatter-plots were used to measure the degree of linear correlation between two quantitative variables.

RESULTS: The Content Validity Index was 0.91. Inter-rater and test-retest reliability were mostly high (Kappa $>0.80$ ), for food availability indicators. Among the items that measure advertising, Kappa values for inter-rater reliability ranged from 0.57 to 1.00 and for the test-retest ranged from 0.18 to 0.90 . Prices and quantity of brands showed a positive linear correlation between measurements performed by researcher 1 and 2 and between visits 1 and 2 .

CONCLUSIONS: AUDITNOVA is reliable for measuring aspects such as availability, price, quantity of brands, and advertising of foods available in the consumer food environment.

Correspondence:

Camila Aparecida Borges

Avenida Dr. Arnaldo, 715

01246-904 São Paulo, SP, Brasil

E-mail: camila.borges@usp.br

Received: Nov 8, 2018

Approved: Apr 4, 2019

How to cite: Borges CA, Jaime PC. Development and evaluation of food environment audit instrument: AUDITNOVA. Rev Saude Publica. 2019;53:91.

Copyright: This is an open-access article distributed under the terms of the Creative Commons Attribution License, which permits unrestricted use, distribution, and reproduction in any medium, provided that the original author and source are credited. 


\section{INTRODUCTION}

The food environment, in its multiple dimensions ${ }^{1}$, influences food consumption and formation of eating habits ${ }^{2,3}$. Strong evidence relates it to the chronic noncommunicable disease (CNCD) epidemic, especially obesity, in developed ${ }^{4,5}$ and developing countries ${ }^{6}$. The food environment is also connected to increased body mass index ${ }^{3}$ and to two important dimensions that ensure food and nutritional security, healthy food access, and availability ${ }^{7}$. Using a socioecological behavior approach, Glanz et al. ${ }^{1}$ suggest a conceptual model that divides the food environment into four main domains: community food environment, organizational food environment, information food environment, and consumer food environment. The latter refers to what consumers find inside and around retail food establishments, for example, healthy food availability, variety, price, promotions, shelf position, nutritional information, and advertising, determining factors in decision-making processes of food acquisition and consumption by the population ${ }^{8,9}$. For example, a study in the United States found only $7 \%$ of the total food information in the weekly circulated leaflet from a supermarket chain was about fruit, $10 \%$ about vegetables, $10 \%$ about milk and dairy products, and $18 \%$ about cereals and grains; moreover, it showed information in these leaflets often influence consumers when making their food purchases ${ }^{10}$.

The Dietary Guidelines for the Brazilian Population (DGBP) also recognizes the role of the food environment in promoting healthy eating and indicates six obstacles that hamper the adherence to current nutritional recommendations: information, advertising, time, cooking skills, cost, and food availability. Four of them are directly related to the food environment (information, advertising, cost, and availability), according to the model by Glanz et al. . Food environment aspects contributing to the health and quality of life of populations have been widely discussed in many countries and motivated the creation of indicator monitoring networks, such as the International Network for Food and Obesity/CNCD Research, Monitoring and Action Support (INFORMAS), a global network of public-interest organizations and researchers from 30 countries that aims to monitor, benchmark and support public and private sector actions to increase healthy food environments and reduce obesity, CNCD and health-related inequalities ${ }^{11}$. INFORMAS proposes food environment monitoring indicators such as food nutritional composition, labeling, food advertising, supply chain, quantity and types of retail food establishments, prices, and investments in the food production chain ${ }^{11}$.

As food environment contributes to obesity and CNCD, as shown in Brazilian technical documents $\mathrm{s}^{7,12,13}$ and international network $\mathrm{s}^{11}$, valid and reliable measures are necessary to study food environment ${ }^{14}$. In the Brazilian scenario, research on this topic is recent ${ }^{6,15,16}$, and studies need to expand production and collection of indicators, especially on the consumer's food environment, which influences the behavior of food purchase and consumption ${ }^{1}$.

None of the audit instruments already validated for the Brazilian context ${ }^{17,18}$ assess food availability and advertising according to the DGBP recommendations. Martins et al. ${ }^{15}$, validating the Brazilian food environment audit instrument based on the adaptation of the study by Glanz et al. ${ }^{14}$, approximate the food groups recommended by the DGBP, but explore only three indicators (availability, price, and quality) and disregard the latest version of the NOVA food classification, which divides them into four groups: in natura/minimally processed, culinary ingredients, processed foods, and ultra-processed foods ${ }^{17-19}$. Brazilian instruments lack indicators that dialogue with national recommendations. Regarding this, identifying the density of commercial establishments that primarily sell ultra-processed foods, the food advertisements according to food type in line with NOVA, the sales of ultra-processed foods in places such as checkout aisles or the sales of in natura products at the establishment entrance and the promotional prices of healthy and unhealthy foods may contribute to the understanding of the relation between food consumption and environment in the face of the new Brazilian nutritional and epidemiological scenario ${ }^{12}$. 
The low reliability of the methods and instruments that propose to analyze the food environment and the current lack of objective criteria in the generation of indicators are barriers to understanding the mechanism of association between food environment, obesity, and food consumption ${ }^{20}$. Thus, this study aims to develop and evaluate the reliability of a food environment audit instrument that enables capturing information of consumer food environment indicators such as availability, price, promotional and advertising strategies, and quantity of brands available, using the dietary recommendations adopted by the DGBP as theoretical basis.

\section{METHODS}

This is a methodological study in two phases: 1. development of the audit instrument and 2. assessment of its reliability and reproducibility. The Ethics Committee of Faculdade de Saúde Pública of Universidade de São Paulo approved this study under CAAE number 69045917.5.0000.5421. All commercial establishments were aware of the informed consent form and voluntarily participated in the study.

\section{Audit Instrument Development}

We designed the NOVA-based food environment audit instrument named AUDITNOVA in stages that involved systematic meetings of the research group; detailed analysis of Brazilian and international audit instruments and detailed analysis of the NOVA food classification proposed by Monteiro et al. ${ }^{17-19}$. The processing of food identified by NOVA involves physical, biological and chemical processes applied after food is separated from nature and before it is eaten or prepared as dishes and meals. NOVA classifies all foods into four major groups:

- group 1: in natura or minimally processed foods. In natura foods are defined as edible parts of plants or animals after leaving nature and minimally processed foods are in natura foods altered by processes that include removal of inedible or unwanted parts and drying, crushing, grinding, fractionating, filtering, roasting, boiling, non-alcoholic fermentation, pasteurization, refrigeration, freezing, and vacuum packaging;

- group 2: culinary ingredients. Substances derived from group 1 or from nature by processes that include pressing, refining, grinding, and drying to make durable products used for cooking and preparing food at home or in restaurants;

- group 3: processed foods. They are essentially made by adding salt, oil, sugar, or other substances from group 2 to group 1 ;

- group 4: ultra-processed foods. Formulations made mainly or entirely from food-derived substances and additives, with little or no food from group $1^{17-19}$.

We selected 66 foods for the AUDITNOVA with the highest frequency of acquisition by the Brazilian population according to data from the 2008-2009 Family Budget Survey (FBS) ${ }^{21}$. The first version of the instrument had two blocks, one on food availability, prices, variety, and quality and another on advertising.

The first version of the instrument underwent the content validation process by a panel of judges with the participation of nine experts distributed among the following areas: food research, food advertising, and consumer protection. DGBP was the theoretical framework adopted during the panel of judges, especially Chapter 2 ("Choosing Food") and Chapter 5 ("Understanding and Overcoming Obstacles"). The judges reviewed each AUDITNOVA item and assigned scores based on the 4-point Likert scale (1: disagree, 2: major revisions are necessary, 3: minor revisions are necessary, and 4: agree) for the clarity, relevance, pertinence, and representativeness attributes. In addition, the judges had a field for writing suggestions if the score was 3 or less. We estimated the content validity index (clear, relevant, pertinent, and representative) for each item and for each instrument block and considered 
it satisfactory when it reached 0.80 agreement among the judges. We discarded items below this percentage in the final version of the instrument ${ }^{22}$.

The final version of AUDITNOVA, after analysis by the panel of judges, contains 14 blocks of questions divided into: block 1 - general information (municipality identification; evaluator identification; commercial establishment identification (sequential number assigned by the researcher); business name and address, date, collection start time and end time); block 2 - establishment type and products sold (type of commercial establishment, food groups sold according to NOVA, food groups sold primarily according to NOVA); block 3 - establishment entrance (fruit and vegetable section at the entrance of the store, food and advertisement availability in checkout aisles); block 4 - fruit and vegetable section (availability, unit of measure, current price in reais/kilo, and price type - normal or promotional); block 5 - meat, chicken, and fish section (availability, most expensive price in reais/kilo, cheapest price in reais/kilo, and price type); block 6 - dairy section (availability, quantity of brands available, most expensive price, cheapest price, and price type); block 7 - grocery section (availability, quantity of brands available, most expensive price, cheapest price, and price type); block $8-$ canned food section (availability, quantity of brands available, most expensive price, cheapest price, and type of price); block 9 - bakery section (availability, quantity of brands available, most expensive price, cheapest price, and type of price); block $10-$ frozen food section (availability, quantity of brands available, most expensive price, cheapest price, and price type); block 11 - beverage section (availability, quantity of brands available, most expensive price, cheapest price, and price type); block $12-$ chocolate and snack section (availability, quantity of brands available, most expensive price, cheapest price, and price type); and finally, blocks 13 and 14 - advertisements inside and outside the establishment, respectively (Supplementary Archive).

\section{Reproducibility and Reliability of the Audit Instrument}

We performed the AUDITNOVA reliability assessment study on a convenience sample in the metropolitan region of the city of São Paulo (SP), easily accessible by public transportation from Faculdade de Saúde Pública. We designed the neighborhood selection to maximize the ability to contrast supermarkets in neighborhoods with different income levels. To guarantee socioeconomic differences between them, we chose sites with different human development indexes (HDI): Pinheiros (HDI = 0.98), Higienópolis (HDI = 0.93), Belém (HDI = 0.91), and Sacomã $(H D I)=0.84)$. In each neighborhood, we selected 20 commercial establishments, among supermarkets, hypermarkets, and markets, totaling a sample of 80 establishments. Only seven refused to participate in the survey. Supermarkets, hypermarkets and markets have various food products available to consumers ${ }^{23,24}$ and are important equipment for measuring the reliability and reproducibility of a food environment audit instrument, as they enable the researcher to apply the instrument integrally.

To assess inter-rater reliability, two trained researchers independently visited the 73 commercial establishments in the region chosen for the study. Inter-rater reliability is used to assess the consistency of a measurement by different evaluators. To assess test-retest reliability, the same researchers revisited 41 sites 32 days after the initial observations. Test-retest reliability is used to assess the consistency of a measurement between two distinct moments.

For categorical variables, percentage agreement and Kappa coefficients assessed inter-rater and test-retest reliability. We quantified Kappa values using the following scale: 0.01 to 0.20 , slight agreement; 0.21 to 0.40 , fair agreement; 0.41 to 0.60 , moderate agreement; 0.61 to 0.80 , substantial agreement; 0.81 to 0.99 , high agreement ${ }^{25}$. We interpreted negative agreement values as a sign that evaluators agreed less on one item than expected due to chance - for example, a systematic disagreement among observers because diverse food items were available in the supermarkets. To assess the reliability of food availability according to NOVA, we grouped the 66 food items in the instrument into: group 1 - sum 
Table 1. AUDITNOVA content validation results: changes and reasons for the changes.

\begin{tabular}{llll}
\hline Item & $\begin{array}{c}\text { Average } \\
\text { CVI* }\end{array}$ & Change & Reasons for the change \\
\hline $\begin{array}{l}\text { Block 1 - Food availability, price, variety, and quality } \\
\text { processed foods does the market sell? }\end{array}$ & $0.97 \quad \begin{array}{c}\text { Inclusion of new in natura foods and division of } \\
\text { food items according to supermarket sections }\end{array}$ & $\begin{array}{c}\text { To audit in natura/minimally processed } \\
\text { foods often consumed by the Brazilian } \\
\text { population and to facilitate data collection }\end{array}$ \\
Item 2. Is FV section located near the store & 0.97 &
\end{tabular}

Item 2. Is FV section located near the store entrance?

Item 3. In natura/minimally processed foods: availability and price

Inclusion of options for price type (normal or 0.89 promotional) and unit of measure ( $\mathrm{kg}$, dozen, unit) for FV; removal of food quality item

Item 4 . Which culinary ingredients does the market sell?

Item 5 Culinary Ingredients: Availability and Price

Item 6 Which processed foods does the market sell?

Item 7. Processed foods: availability and price

Item 8. Which ultra-processed foods does the market sell?

Item 9. Ultra-processed foods: availability and price

Inclusion of new items; distribution of items by supermarket section

Inclusion of price type (normal or promotional), quantity of brands, most expensive and cheapest price; standardization of items

Inclusion of new items; distribution of items by supermarket section

Inclusion of price type (normal or promotional), quantity of brands, most expensive and cheapest price; standardization of items

Inclusion of new items; distribution of items by supermarket section

Inclusion of price type (normal or promotional), 0.90 quantity of brands, most expensive and cheapest price; standardization of items

Block 2 - publicity and advertising

Item 1. Visual advertising encouraging FV purchase

Item 2. Advertising type verified in FV

section

Item 3. Appeal and reason for the

advertising in the FV section

Item 4 . Visual advertising that encourages

the purchase of sugary drinks such as added

sugar juices, nectars, and soft drinks.

Item 5. Types of sugary drink advertisements

Item 6. Appeal and reason for the

advertising in the sugary drink section

Item 7. Visual advertising encouraging the purchase of crackers, cookies and cornmeal snacks in the sections where these foods can be found.

Item 8. Crackers/Cookies/Cornmeal snacks: Types of Advertisements

Item 9. Appeal and reason for the advertising in the cookie/cracker/snack section

Item 10. Are there any health promotion or advertising messages related to food and health in the establishment?

Item 11 . Write down the messages

Item 12. Do the checkout aisles have magazines/posters/folders with news about fad diets, superfoods, diet versus light and/ or other food and health news?

Item 13. Do the checkout aisles sell chocolates, treats, soft drinks, energy drinks or other types of ultra-processed products? Item 14. Do the checkout aisles have ultraprocessed food advertising?

Total CVI of the instrument

$$
\text { Deleted and made into new items }
$$

Each type became a new questionnaire item

Each appeal and reason became a new item in the questionnaire.

Deleted and made into new items to evaluate ultraprocessed advertising in general

Deleted and made into new items to evaluate ultraprocessed advertising in general

The most relevant appeals and reasons became new items in the questionnaire.

Deleted and made into new items to evaluate ultraprocessed advertising in general

Deleted and made into new items to evaluate ultraprocessed advertising in general

The most relevant appeals and reasons became new items in the questionnaire.

No changes, but applied to in natura/minimally processed and ultra-processed foods

Deleted

Each food was detailed in a new item

More detailed characterization of the checkout aisle
New embedded items were able to capture the variability of advertisements

New embedded items were able to capture the variability of advertisements

New embedded items were able to capture the variability of advertisements

New embedded items were able to capture the variability of advertisements

New embedded items were able to capture the variability of advertisements

New embedded items were able to capture the variability of advertisements

New embedded items were able to capture the variability of advertisements

New embedded items were able to capture the variability of advertisements

New embedded items were able to capture the variability of advertisements

This theme applies to many types of healthy and unhealthy foods

New embedded items were able to capture the variability of advertisements
Units of measure variation hindering price collection; low ability to distinguish food quality

To audit culinary ingredients frequently consumed by the Brazilian population and to facilitate data collection

To audit more details of culinary ingredients

To audit processed foods often consumed by the Brazilian population and to facilitate data collection

To audit more details of processed foods

To audit ultra-processed foods often consumed by the Brazilian population and to facilitate data collection

To audit more details of ultra-processed foods

FV: fruits and vegetables; checkout: areas where the cash registers of the commercial establishments are located

*The CVI (content validity index) represents the average score given by the nine expert judges for the clarity, relevance, pertinence, and representativeness attributes. 
Table 2. Reliability of the AUDITNOVA instrument according to indicators of food availability.

\begin{tabular}{|c|c|c|c|c|c|c|}
\hline \multirow{2}{*}{ Types of Foods Available } & \multicolumn{3}{|c|}{ Inter-rater reliability } & \multicolumn{3}{|c|}{ Test-retest reliability } \\
\hline & $\mathbf{n}$ & agreement \% & Kappa & $\mathbf{n}$ & agreement $\%$ & Kappa \\
\hline In natura/Minimally Processed Foods & 72 & 59.7 & 0.55 & 41 & 55.8 & 0.52 \\
\hline Orange & 73 & 100.0 & 1.00 & 41 & 92.7 & 0.88 \\
\hline Banana & 73 & 94.5 & 0.72 & 41 & 82.9 & 0.72 \\
\hline Formosa papaya & 72 & 100.0 & 1.00 & 41 & 78.5 & 0.61 \\
\hline Fuji apple & 73 & 93.1 & 0.70 & 41 & 90.2 & 0.79 \\
\hline Watermelon & 72 & 97.2 & 0.93 & 41 & 85.4 & 0.74 \\
\hline Other fruits & 73 & 98.6 & 0.85 & 41 & 97.6 & 0.94 \\
\hline Tomato & 73 & 93.1 & 0.83 & 41 & 90.2 & 0.84 \\
\hline Onion & 73 & 98.6 & 0.85 & 41 & 92.7 & 0.84 \\
\hline Lettuce & 73 & 100.0 & 1.00 & 41 & 87.8 & 0.78 \\
\hline Carrot & 73 & 98.6 & 0.90 & 41 & 78.0 & 0.64 \\
\hline Zucchini & 73 & 91.8 & 0.75 & 41 & 87.8 & 0.79 \\
\hline Chayote & 73 & 98.6 & 0.91 & 41 & 92.7 & 0.86 \\
\hline Mix of parsley, spring onion, and cilantro & 73 & 95.9 & 0.88 & 41 & 82.9 & 0.71 \\
\hline Other vegetables & 73 & 97.3 & 0.78 & 41 & 92.7 & 0.86 \\
\hline Potato & 73 & 98.6 & 0.90 & 41 & 85.4 & 0.72 \\
\hline Cassava & 73 & 98.6 & 0.97 & 41 & 65.8 & 0.44 \\
\hline Other roots and tubers & 73 & 94.5 & 0.64 & 41 & 95.1 & 0.90 \\
\hline Sweet corn & 73 & 94.5 & 0.87 & 41 & 73.2 & 0.57 \\
\hline Eggs & 73 & 94.5 & 0.84 & 41 & 75.6 & 0.6 \\
\hline Other eggs & 73 & 97.3 & 0.90 & 41 & 85.4 & 0.74 \\
\hline Prime beef & 73 & 100.0 & 1.00 & 41 & 87.8 & 0.81 \\
\hline Choice beef & 73 & 98.6 & 0.97 & 41 & 87.8 & 0.81 \\
\hline Chicken & 73 & 98.6 & 0.96 & 41 & 80.5 & 0.68 \\
\hline Chicken Breast & 73 & 98.6 & 0.85 & 41 & 95.1 & 0.90 \\
\hline Fish & 73 & 98.6 & 0.93 & 41 & 100.0 & 1.00 \\
\hline Cow milk & 73 & 100.0 & 1.00 & 41 & 97.6 & 0.95 \\
\hline Pinto beans & 73 & 100.0 & 1.00 & 41 & 95.1 & 0.91 \\
\hline Black turtle beans & 73 & 100.0 & 1.00 & 41 & 90.2 & 0.82 \\
\hline White rice & 73 & 100.0 & 1.00 & 41 & 97.6 & 0.95 \\
\hline Wheat flour & 73 & 100.0 & 1.00 & 41 & 100.0 & 1.00 \\
\hline Cassava flour & 73 & 98.6 & 0.79 & 41 & 87.8 & 0.73 \\
\hline Spaghetti & 73 & 98.6 & 0.93 & 41 & 100.0 & 1.00 \\
\hline Raw peanut & 73 & 90.4 & 0.70 & 41 & 75.6 & 0.56 \\
\hline $500 \mathrm{ml}$ Water & 73 & 100.0 & a & 41 & 97.6 & 0.95 \\
\hline 5-liter gallon Water & 73 & 100.0 & 1.00 & 41 & 73.2 & 0.55 \\
\hline Culinary Ingredients & 73 & 93.1 & 0.87 & 41 & 70.7 & 0.64 \\
\hline Butter & 73 & 100.0 & 1.00 & 41 & 92.7 & 0.86 \\
\hline Soybean oil & 73 & 100.0 & a & 41 & 95.1 & 0.89 \\
\hline Olive oil & 73 & 100.0 & 1.00 & 41 & 97.6 & 0.93 \\
\hline Refined salt & 73 & 98.6 & 0.79 & 41 & 100.0 & 1.00 \\
\hline Sanding Sugar & 73 & 94.5 & 0.88 & 41 & 80.5 & 0.68 \\
\hline White Sugar & 73 & 100.0 & a & 41 & 100.0 & 1.00 \\
\hline Processed foods & 73 & 94.5 & 0.89 & 41 & 68.3 & 0.61 \\
\hline Bacon & 73 & 98.6 & 0.91 & 41 & 92.7 & 0.86 \\
\hline Dried meat & 73 & 97.3 & 0.93 & 41 & 80.5 & 0.70 \\
\hline Cheese & 73 & 100.0 & a & 41 & 97.6 & 0.94 \\
\hline
\end{tabular}

Continue 
Table 2. Reliability of the AUDITNOVA instrument according to indicators of food availability. Continuation

\begin{tabular}{|c|c|c|c|c|c|c|}
\hline Canned Corn & 73 & 100.0 & 1.00 & 41 & 97.6 & 0.95 \\
\hline Tomato purée & 73 & 100.0 & 1.00 & 41 & 100.0 & 1.00 \\
\hline Canned Sardines & 73 & 98.6 & 0.79 & 41 & 97.6 & 0.95 \\
\hline Bread roll & 73 & 100.0 & 1.00 & 41 & 82.9 & 0.68 \\
\hline Ultra-Processed Foods & 73 & 82.2 & 0.76 & 41 & 61.0 & 0.57 \\
\hline Hot dog sausage & 73 & 100.0 & 1.00 & 41 & 95.1 & 0.91 \\
\hline Pork Sausage & 73 & 93.1 & 0.80 & 41 & 90.2 & 0.82 \\
\hline Fermented milk & 73 & 98.6 & 0.95 & 41 & 92.7 & 0.86 \\
\hline Instant noodle & 73 & 98.6 & 0.88 & 41 & 90.2 & 0.80 \\
\hline Ready-made seasoning & 73 & 100.0 & 1.00 & 41 & 100.0 & 1.00 \\
\hline Sliced bread & 73 & 97.3 & 0.78 & 41 & 90.2 & 0.79 \\
\hline Breakfast Cereals & 73 & 98.6 & 0.88 & 41 & 97.6 & 0.94 \\
\hline Frozen pizza & 73 & 100.0 & 1.00 & 41 & 95.1 & 0.90 \\
\hline Ice cream & 73 & 98.6 & 0.94 & 41 & 85.4 & 0.73 \\
\hline Regular Can Soda ${ }^{a}$ & 73 & 100.0 & 1.00 & 41 & 100.0 & 1.00 \\
\hline Regular 2-liter Soda ${ }^{b}$ & 73 & 100.0 & 1.00 & 41 & 100.0 & 1.00 \\
\hline Zero/zero sugar/diet soda & 73 & 100.0 & 1.00 & 41 & 97.6 & 0.94 \\
\hline Nectar & 73 & 100.0 & 1.00 & 41 & 100.0 & 1.00 \\
\hline Fruit juice drink & 73 & 100.0 & 1.00 & 41 & 100.0 & 1.00 \\
\hline Cornmeal snacks & 73 & 100.0 & 1.00 & 41 & 100.0 & 1.00 \\
\hline Sandwich cookie & 73 & 100.0 & a & 41 & 100.0 & a \\
\hline Chocolate & 73 & 95.9 & 0.80 & 41 & 92.7 & 0.85 \\
\hline Candies & 73 & 97.3 & 0.94 & 41 & 97.5 & 0.96 \\
\hline
\end{tabular}

a Statistics could not be estimated because the cross tabulation had two or fewer levels.

b Soda with added sugar.

Table 3. Reliability of the AUDITNOVA instrument according to food availability indicators, and price types according to NOVA.

\begin{tabular}{|c|c|c|c|c|c|c|}
\hline \multirow{2}{*}{$\begin{array}{l}\text { Indicators of availability of food groups and price type } \\
\text { according to NOVA }\end{array}$} & \multicolumn{3}{|c|}{ Inter-rater reliability } & \multicolumn{3}{|c|}{ Test-retest reliability } \\
\hline & $\mathbf{n}$ & agreement \% & Kappa & $\mathrm{n}$ & agreement \% & Kappa \\
\hline FV at the store entrance & 73 & 95.9 & 0.92 & 41 & 97.6 & 0.95 \\
\hline \multicolumn{7}{|l|}{ Food groups sold } \\
\hline In natura/minimally processed Foods & 73 & 100.0 & * & 41 & 100.0 & $*$ \\
\hline Culinary ingredients & 73 & 100.0 & * & 41 & 100.0 & * \\
\hline Processed foods & 73 & 100.0 & * & 41 & 100.0 & $*$ \\
\hline Ultra-processed Foods & 73 & 100.0 & * & 41 & 100.0 & * \\
\hline \multicolumn{7}{|l|}{ Primarily sold food groups } \\
\hline In natura/minimally processed foods & 73 & 75.3 & 0.69 & 41 & 90.2 & 0.78 \\
\hline Culinary ingredients & 73 & 97.3 & 0.75 & 41 & 95.1 & 0.88 \\
\hline Processed foods & 73 & 87.7 & 0.36 & 41 & 95.1 & 0.90 \\
\hline Ultra-processed Foods & 73 & 91.8 & 0.78 & 41 & 100.0 & 1.00 \\
\hline \multicolumn{7}{|l|}{ Price type (normal or promotional) } \\
\hline In natura/minimally processed Foods & 73 & 93.0 & 0.90 & 41 & 93.6 & 0.89 \\
\hline Culinary ingredients & 73 & 81.1 & 0.77 & 41 & 82.1 & 0.78 \\
\hline Processed foods & 73 & 71.4 & 0.61 & 41 & 70.4 & 0.58 \\
\hline Ultra-Processed Foods & 73 & 61.7 & 0.56 & 41 & 52.6 & 0.48 \\
\hline
\end{tabular}

FV: Fruits and Vegetables

* Statistics could not be estimated because the cross tabulation had two or fewer levels. 
Table 4. Reliability of the AUDITNOVA instrument according to advertising indicators, and food advertising strategies according to the NOVA classification.

\begin{tabular}{|c|c|c|c|c|c|c|}
\hline \multirow{2}{*}{ Types of Advertisements and Advertising Strategies } & \multicolumn{3}{|c|}{ Inter-rater reliability } & \multicolumn{3}{|c|}{ Test-retest reliability } \\
\hline & n & agreement \% & Kappa & $\mathbf{n}$ & agreement \% & Kappa \\
\hline \multicolumn{7}{|l|}{ Checkout aisle advertisements } \\
\hline In natura/minimally processed food advertisements of different types & 73 & 89.0 & 0.57 & 41 & 90.2 & 0.77 \\
\hline UPF food advertising of different types & 73 & 93.1 & 0.81 & 41 & 92.7 & 0.83 \\
\hline Tabloid & 73 & 94.5 & 0.90 & 41 & 94.5 & 0.90 \\
\hline Folder or leaflet & 73 & 98.6 & 0.88 & 41 & 95.1 & 0.79 \\
\hline \multicolumn{7}{|l|}{ Approaches in physical space } \\
\hline In natura food flags & 73 & 87.7 & 0.65 & 41 & 87.8 & 0.72 \\
\hline In natura food banner/posters & 72 & 84.7 & 0.60 & 41 & 82.5 & 0.52 \\
\hline In natura food displays & 73 & 89.0 & 0.65 & 41 & 87.8 & 0.46 \\
\hline In natura food tabloids & 73 & 87.7 & 0.75 & 41 & 65.8 & 0.39 \\
\hline In natura food recipes folder/leaflet & 73 & 91.8 & 0.65 & 41 & 90.2 & 0.55 \\
\hline UPF food displays & 73 & 100.0 & 1.00 & 41 & 95.2 & * \\
\hline UPF food promotional islands & 73 & 86.3 & 0.67 & 41 & 68.3 & 0.37 \\
\hline UPF food endcaps & 73 & 82.2 & 0.66 & 41 & 72.5 & 0.48 \\
\hline UPF food tasting counters & 73 & 97.3 & 0.74 & 41 & 95.1 & * \\
\hline \multicolumn{7}{|l|}{ Message types and consumer appeals } \\
\hline Food functional property with in natura food & 73 & 98.6 & 0.95 & 41 & 87.8 & 0.72 \\
\hline Physical activity and in natura food & 73 & 98.6 & 0.66 & 41 & 95.1 & 0.62 \\
\hline $\begin{array}{l}\text { Wellness, good mood, self-esteem with in natura/minimally processed } \\
\text { food }\end{array}$ & 73 & 91.8 & 0.62 & 41 & 92.7 & 0.70 \\
\hline Health claim with in natura food & 72 & 95.8 & 0.84 & 41 & 82.9 & 0.72 \\
\hline Appeal to practicality with in natura/minimally processed food & 73 & 94.5 & 0.68 & 41 & 92.7 & 0.67 \\
\hline $\begin{array}{l}\text { Highlight in in natura/minimally processed food flavor, odor, color, or } \\
\text { texture }\end{array}$ & 72 & 94.4 & 0.84 & 41 & 87.8 & 0.48 \\
\hline Health and wellness claim with UPF food & 73 & 86.3 & 0.72 & 41 & 78.0 & 0.58 \\
\hline Appeal for practicality with UPF food & 73 & 84.9 & 0.62 & 41 & 56.1 & 0.23 \\
\hline Functional property with UPF & 73 & 84.9 & 0.68 & 41 & 72.5 & 0.41 \\
\hline Highlight in UPF food flavor, odor, color, or texture & 73 & 90.4 & 0.80 & 41 & 65.8 & 0.43 \\
\hline \multicolumn{7}{|l|}{ Advertisements about tastings, giveaways, promotions, and releases } \\
\hline Take 3 , pay 2 with in natura food & 73 & 98.6 & * & 41 & 97.6 & * \\
\hline In natura/minimally processed product launches & 72 & 98.6 & * & 41 & * & * \\
\hline Natura/minimally processed giveways or tie-in sales & 73 & 95.9 & 0.64 & 41 & * & * \\
\hline UPF free samples & 73 & 98.6 & * & 41 & 95.6 & * \\
\hline Take 3, pay 2 with UPF & 73 & 87.7 & 0.71 & 41 & 78.0 & 0.46 \\
\hline UPF releases & 73 & 78.1 & 0.62 & 41 & 53.6 & 0.18 \\
\hline UPF giveaways or tie-in sales & 73 & 79.4 & 0.61 & 41 & 73.2 & 0.46 \\
\hline Advertising in general with culinary ingredients & 73 & 86.3 & 0.70 & 41 & 61.0 & 0.18 \\
\hline Processed food advertising in general & 73 & 80.8 & 0.65 & 41 & 61 & 0.20 \\
\hline \multicolumn{7}{|l|}{ Advertisements outside the establishment } \\
\hline Advertising in general with in natura/minimally processed foods & 73 & 90.4 & 0.70 & 41 & 78.0 & 0.61 \\
\hline Advertising in general of culinary ingredients & 73 & 94.5 & 0.77 & 41 & 80.5 & 0.66 \\
\hline Advertising of processed foods in general & 73 & 94.5 & 0.82 & 41 & 75.6 & 0.58 \\
\hline UPF advertising outside the establishment & 73 & 93.1 & 0.85 & 41 & 78.5 & 0.60 \\
\hline
\end{tabular}

Checkout: areas where cash registers are located in commercial establishments; UPS: Ultra-Processed Foods

*Statistics could not be estimated because the cross tabulation had two or fewer levels. 
of all in natura/minimally processed foods; group $2-$ sum of all culinary ingredients; group 3 - sum of all processed foods, and group 4 - sum of all ultra-processed foods.

For quantitative variables such as price and quantity of brands available, we first performed an exploratory analysis using scatter plots illustrating the linear fit and the quadratic fit. Scatter plots allow identifying patterns in data distribution and possible systematic and random errors depending on how dots are distributed along the line ${ }^{26}$. Subsequently, we estimated Pearson's correlation coefficient (r), which measures the degree of linear correlation between two quantitative variables. It is a dimensionless index with values between -1.0 and 1.0, which reflects the intensity of a linear relationship between two data sets. We estimated Pearson's correlation coefficient between the pairs of variables collected by researcher 1 and researcher 2 and between the variables collected on the first and second visits. We estimated price and brand averages for each of the four food groups analyzed. We performed statistics on the statistical package Stata 14.

\section{RESULTS}

At the content validation stage conducted by nine judges, the experts provided the necessary information to review the audit instrument and improve its content. The content validity index (CVI), which represents the average score for the clarity, relevance, pertinence, and representativeness attributes, was 0.91 for the entire instrument. Although the CVI was greater than 0.80 for most items, the suggestions provided by the experts were incorporated
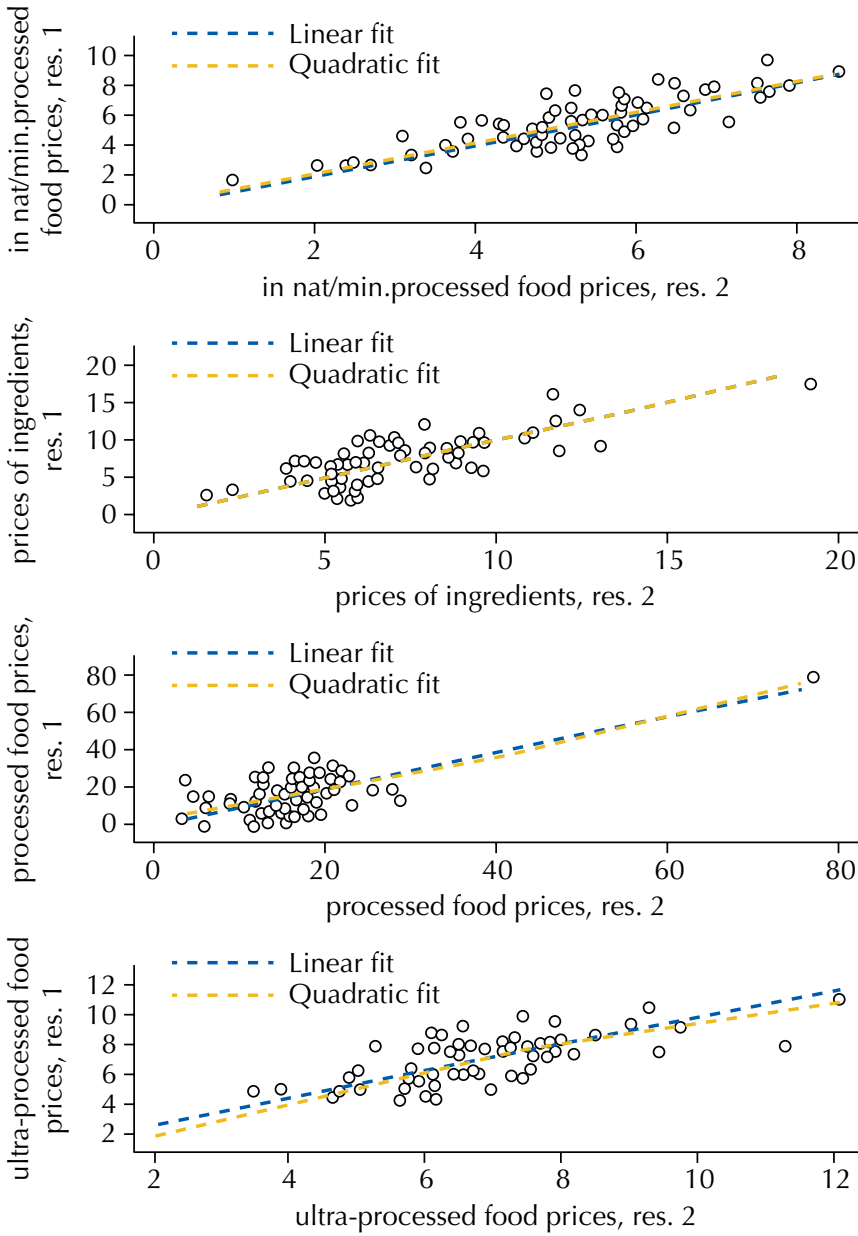

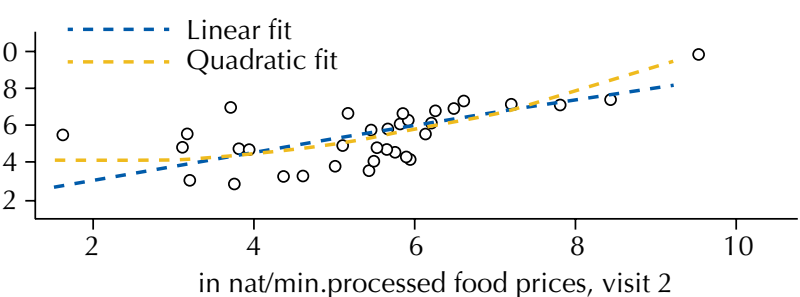

in nat/min.processed food prices, visit 2
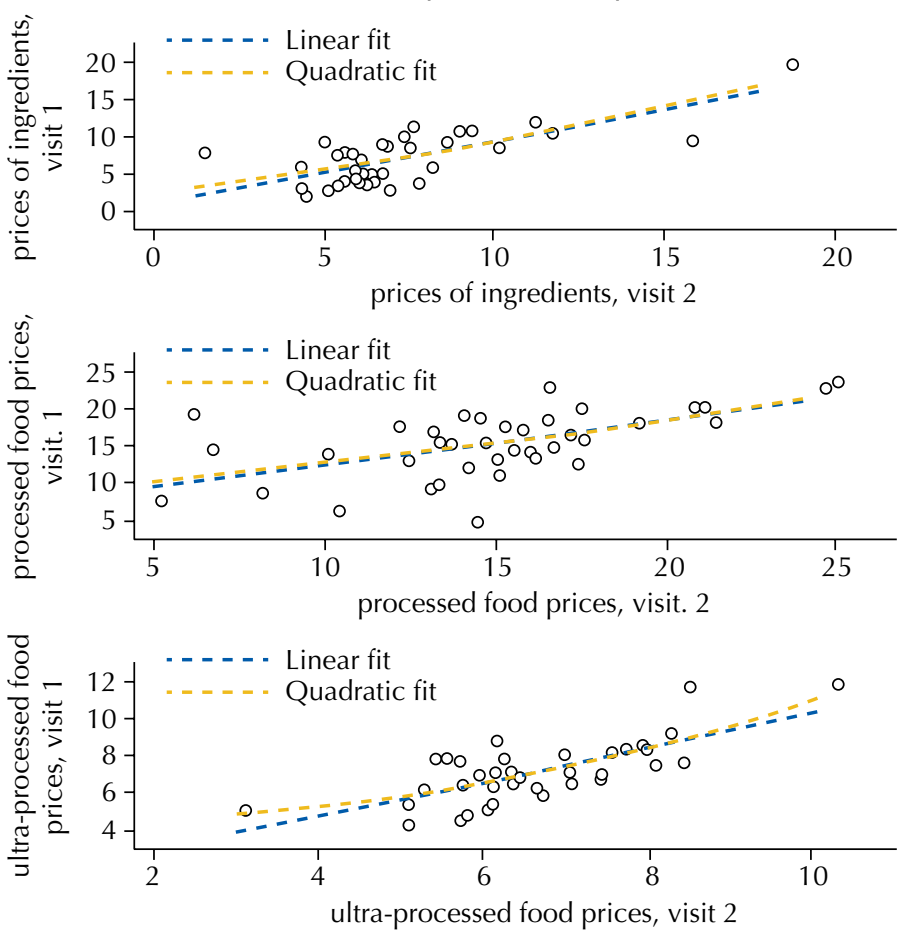

Res: researcher; in nat/min.processed: in natura and minimally processed

Figure 1. Relationship between food price variables according to NOVA collected by researchers 1 and 2 at the first and second visit. 
into the instrument because they are totally suitable according to the researcher's assessment (Table 1).

During the audit process, both trained researchers' first visits to the 73 establishments occurred in an average of 41 days (standard deviation $=11.8$ days). The average application time of AUDITNOVA was 90 minutes (standard deviation $=7.0$ minutes). The researchers' second visit occurred between 32 and 47 days after the first collection, with an average of 39.5 days (standard deviation $=4.8$ days).

Table 2 shows the inter-rater and test-retest reliability results for the 66 audited foods and for the four NOVA food groups. Most foods had Kappa values higher than 0.80 (substantial agreement) for both inter-rater and test-retest. Analyzing the NOVA groups, we found in natura/minimally processed foods showed moderate Kappa values (0.41-0.60) for both inter-rater and test-retest. The other three food groups (culinary ingredients, processed foods, and ultra-processed foods) had Kappa values above 0.70 for inter-rater reliability, ranging from 0.57 to 0.64 for test-retest reliability, which indicates moderate agreement between visits.

Table 3 shows the inter-rater and test-retest reliability results for the sold and primarily sold foods according to NOVA indicators, fruit and vegetable section at the entrance of the establishment and price type (normal or promotional) for foods grouped according to NOVA. Despite the high agreements observed for all indicators, Kappa values in both inter-rater and test-retest reliability were reasonable (0.21-0.40) and moderate (0.41-0.60), showing the low capacity of agreement of some, such as priority sale of processed foods and price type of ultra-processed foods.
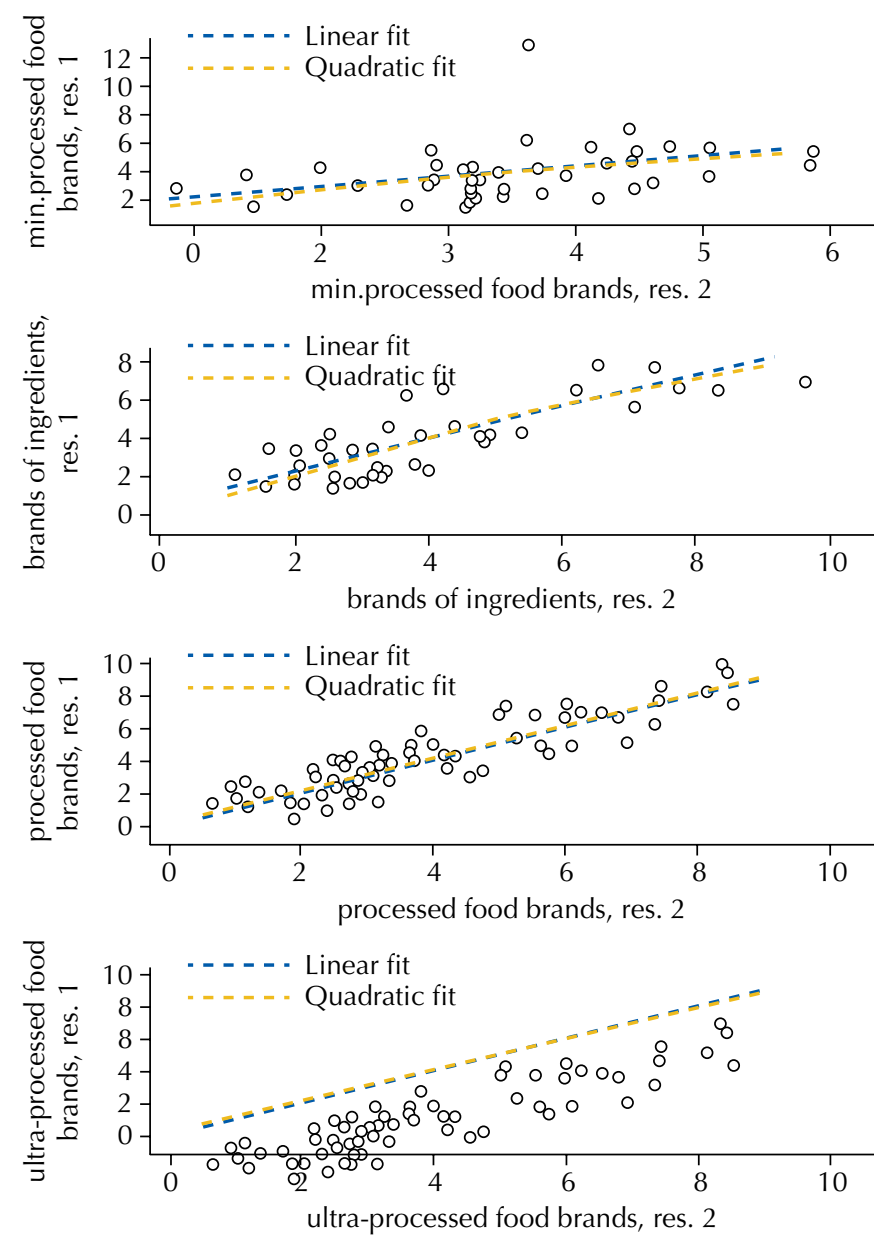
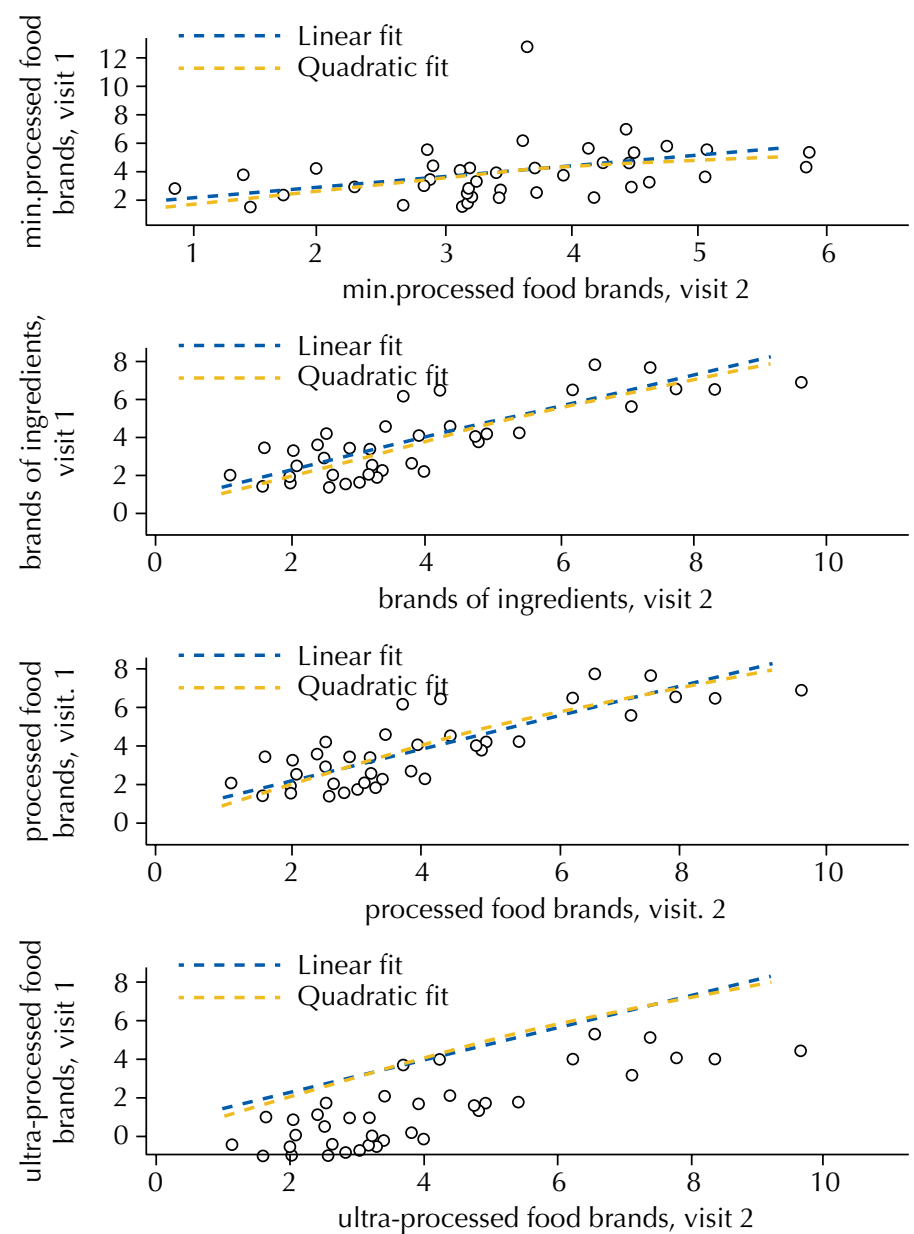

Res: researcher; min .processed: minimally processed

Figure 2. Relationship between food price variables according to NOVA collected by researchers 1 and 2 at the first and second visit. 
Table 5. Mean and standard deviation (SD) of price and quantity of brands collected by researchers 1 and 2 and at visits 1 and 2 , and Pearson's correlation coefficient ( $r$ ) values between pairs of variables.

\begin{tabular}{|c|c|c|c|c|c|c|}
\hline \multirow{2}{*}{ Quantitative variables } & \multicolumn{3}{|c|}{ Inter-rater } & \multicolumn{3}{|c|}{ Test-retest } \\
\hline & Mean (SD) Researcher 1 & Mean (SD) Researcher 2 & $\mathbf{r}$ & Mean (SD) Visit 1 & Mean (SD) Visit 2 & $\mathbf{r}$ \\
\hline $\begin{array}{l}\text { In natura/minimally processed } \\
\text { food price }\end{array}$ & $5.34(1.51)$ & $5.28(1.42)$ & 0.98 & $5.51(1.26)$ & $5.35(1.47)$ & 0.82 \\
\hline Price of ingredients & $7.17(2.68)$ & $7.15(2.61)$ & 0.99 & $7.12(2.66)$ & $7.11(2.86)$ & 0.90 \\
\hline Processed food price & $16.14(8.41)$ & $16.34(8.59)$ & 0.97 & $15.09(4.23)$ & $15.04(4.28)$ & 0.65 \\
\hline Ultra-processed food price & $6.85(1.53)$ & $6.67(1.59)$ & 0.95 & $6.93(1.60)$ & $6.63(1.36)$ & 0.84 \\
\hline Minimally processed food brands & $3.45(1.19)$ & $3.51(1.62)$ & 0.75 & $3.91(1.73)$ & $3.46(1.10)$ & 0.47 \\
\hline Ingredient Brands & $3.88(2.05)$ & $3.85(2.01)$ & 0.98 & $3.91(1.89)$ & $4.01(2.09)$ & 0.93 \\
\hline Processed food brands & $3.09(1.18)$ & $3.10(1.23)$ & 0.96 & $3.35(1.15)$ & $3.13(1.20)$ & 0.89 \\
\hline Ultra-processed food brands & $4.19(1.35)$ & $4.00(1.21)$ & 0.97 & $4.32(1.06)$ & $4.24(1.11)$ & 0.92 \\
\hline
\end{tabular}

Table 4 shows the inter-rater and test-retest reliability results for the advertising variables in AUDITNOVA. The inter-rater reliability obtained a higher number of Kappa coefficients above 0.80 than the test-retest. For inter-rater reliability, Kappa values ranged from 0.57 to 1.00 , and for the test-retest, from 0.18 to 0.90 - the highest disagreement.

Figure 1 shows the scatter plots illustrating the relationship between food price variables according to NOVA collected by researchers 1 and 2 and collected on the first and second visit. The inclinations of the lines show a positive correlation in all cases.

Figure 2 shows the scatter plots illustrating the relation between the variables quantity of food brands according to NOVA, collected by researchers 1 and 2 and collected at the first and second visit. The inclinations of the lines show a positive correlation in all cases.

Table 5 shows the average values of price and quantity of brands found by researchers 1 and 2 at each visit, as well as the Pearson correlation (r) values of the pairs of variables analyzed. Although all correlation values were positive, the quantity of minimally processed food brands had the lowest $r$ values both among evaluators and between visits.

\section{DISCUSSION}

The food environment audit instrument developed in this study, AUDITNOVA, had high inter-rater and test-retest reliability, which ensures that it is a reliable instrument for studies aimed at working with food environment indicators based on the NOVA food classification proposed by Monteiro et al. ${ }^{17}$. We carefully selected the indicator foods of the four groups proposed in NOVA because Brazilians frequently purchase them, according to national surveys, and DGBP recommends them. These foods included in AUDITNOVA may assess retail establishments regarding their availability of healthy and unhealthy foods according to Brazilian guidelines ${ }^{12}$. In addition, information about price, quantity of brands and advertising will enable assessing the consumer's food environment in detail, observing the barriers and conveniences that consumers face when choosing their food ${ }^{1}$. Most of the indicators in this instrument are appropriate for the planning of policy programs aimed at modifying the environment, assessing intervention needs and population needs when faced with food availability, and serving as evaluation, surveillance and advocacy indicators for other actions based on the consumer's food environment ${ }^{20}$.

High inter-rater reliability shows the definitions and instructions in the measurement manual and training methods were sufficient to prepare observers to collect high-quality data. The high test-retest reliability in most of the indicators suggests only minor changes in food availability, price, quantity of brands, and advertising strategies occur over the data collection period. Thus, the measures collected with AUDITNOVA generated a stable estimate of the consumer's food environment. However, the availability and price of in 
natura/minimally processed foods often change over the seasons; therefore, whenever the instrument is reapplied, repeated observations should be considered to assess or control seasonal effects ${ }^{14}$.

In Brazil, studies on food environment are recent, Martins et al..$^{15}$ and Duran et al. ${ }^{16}$ developed and validated pioneering instruments for auditing the community food environment and the consumer food environment. The audit instrument validated by Martins et al. ${ }^{15}$ is an adaptation of the one developed by Glanz et al. ${ }^{14}$ to measure the consumer food environment, specifically retail food establishments, and to assess aspects such as food availability, price, and quality with a food list guided by the food pyramid and the degree of processing. However, it disregards the full version of the NOVA classification. Duran et al. ${ }^{16}$ proposed an audit instrument designed to audit retail food establishments and restaurants and to measure aspects such as availability, variety, quality, price, and advertising of healthy food indicators such as fruits and vegetables and of unhealthy food indicators such as ultraprocessed foods. The main differences of the AUDITNOVA developed and validated in this study comparing with the other two Brazilian instruments were the full use of the NOVA classification in the food item selection, the expansion of advertising and promotional strategies by food groups, the availability of 66 food items (including culinary ingredients and processed foods), the inclusion of strategic aspects of the consumer food environment (such as checkout aisles, endcaps, and islands), and the collection of information on normal or promotional prices, determining factors in the food acquisition by the population ${ }^{1,9,14,20}$.

The main indicators proposed in this instrument showed substantial and high Kappa values. Kappa values were moderate for the indicator of availability of in natura/minimally processed foods, especially in the test-retest, but Kappa values were substantial when evaluating food items in isolation. However, the seasonality and the low variety of in natura/ minimally processed foods in supermarkets and markets compared with street markets, big retail markets and farmer's markets may have influenced the indicator reliability ${ }^{24,27}$.

AUDITNOVA enables measuring the different food information sources available in the consumer food environment in detail, dividing the types of advertising according to the NOVA's four food groups. The DGBP recognizes that the publicity and information available in the consumer food environment can become an obstacle for the population to reach the food recommendations ${ }^{12}$, because large food industries, especially the ultra-processed food ones, use the advertisements to sell more products, not to educate consumers ${ }^{28}$.

The World Health Organization also recognizes that the massive advertising campaigns adopted by the food industries, especially those aimed at children and with different appeals (health, fitness, convenience, releases, children's characters, among others), affect these individuals' health. Thus, countries should review the regulatory processes regarding the propagation of these advertisements on packaging and in the mainstream media ${ }^{28}$. Concerning this, the development of audit instruments that provide an overview of these advertising practices in the consumer food environment and corroborate the DGBP will be essential for the advancement of public policies and regulation. Dietary environment indicators that enable producing more evidence about their influence are part of the strategy to face obesity and $\mathrm{CNCD}^{5}$.

The advertising variables measured by AUDITNOVA showed higher inter-rater reliability than in the test-retest, including many values that could not be computed due to the low availability of advertisements in the establishments. Duran et al. also observed this fact in their study ${ }^{16}$, and it may indicate the researcher's difficulty in identifying the different advertising strategies available in the retail establishment and in knowing how to distinguish, in particular, the types of appeals that these advertisements bring. Advertisements with Kappa values lower than 0.40 in the test-retest were: tabloids with in natura/minimally processed food advertisements, promotional islands with ultra-processed foods, appeal to the convenience of ultra-processed foods, ultra-processed food launches, and advertisements of culinary ingredients and processed foods, in general. One hypothesis to improve the 
reliability of this indicator would be to conduct more than one field researcher training throughout the audit process to reaffirm the different types of appeal and approaches of food advertising in retail and/or to expand the sample of audited establishments to increase the prevalence of these types of advertising. However, researchers can still use the instrument in the field. As the instrument is built in independent blocks, they will be free to select the indicators that best fit their research goals.

The variables price and quantity of brands showed positive correlations between the measurements made by researchers 1 and 2 and visits 1 and 2. Both price and quantity of brands influence consumers when buying food ${ }^{29-31}$. Measuring these aspects reliably, even over a certain time range, is essential for the use of the instrument in the monitoring and mapping of these indicators in different commercial establishments and in different social realities.

Although this study disregarded the food environment throughout the year, at certain times (for example, Christmas, Easter, Father's Day, and Mother's Day), price, availability, and especially advertising indicators $\mathrm{s}^{\mathrm{a}}$ may vary beyond expected due to advertising campaigns and new products available on those dates. Therefore, the researcher must assess the necessity of applying the instrument in these periods.

Some of the strengths of this study are the content validation process prepared by a panel of judges specialized in food environment and food advertising, and the use of the NOVA food classification as a theoretical and analytical framework. In addition, the use of Brazilian databases, such as that of Pesquisa de Orçamentos Familiares (POF - Brazilian Family Budget Survey), provided subsidies for selecting foods that are frequently purchased by the Brazilian population. Another strength of the study is the presence of foods in greater variety in relation to Brazilian instruments, enabling the grouping according to NOVA, as well as the inclusion of more complete information on advertising, prices and quantity of brands, which may provide a more detailed overview of food environment for researchers who will use the instrument.

One of the limitations of this study is the convenience sample of only one Brazilian city and the low variety of audited business types (supermarkets, hypermarkets, and markets only). This sample does not represent the municipality and the country; however, neighborhoods have significant socioeconomic variations that may impact the food availability audited. Another limitation is the lack of evaluation of seasonal differences during the year. The instrument evaluated only retail establishments used by the population for food purchase and not for immediate consumption, such as bars and restaurants. As many individuals eat out in Brazil ${ }^{21}$, developing and validating appropriate instruments to audit these places according to the new national food recommendations is necessary. This study did not use a quality indicator of retail food establishments based on possible scores generated by the instrument, a fact recognized as important, which will be considered for future studies.

The instrument developed, AUDITNOVA, proved to be reliable for audits in the food environment, especially in the consumer food environment, as it enables an overview of types of retail equipment in the territory and a broad analysis of the main determinants that contribute to supporting the population to choose healthier food. AUDITNOVA is reliable for measuring aspects such as availability, price, quantity of brands, and food advertising. Associations between food environment, food consumption, and obesity are becoming more frequent; however, reliable data collection instruments are needed to reach these results. The development and validation of a food environment audit instrument based on the recommendations presented in the DGBP dialogues with other Brazilian policies and supports the development of evidence that allows us to rethink the role of the food environment in availability, access, and consequently, food and nutritional security of the Brazilian population. We published the data collection training manual developed in this investigation and the AUDITNOVA instrument, which are available for download at: http://colecoes.sibi.usp.br/fsp/items/show/3364\#?c=0\&m=0\&s =0\&cv=0. 
Research supported by the International Development Research Center (IDRC) and the Brazilian Institute of Consumer Protection (Instituto Brasileiro de Defesa do Consumidor - IDEC) for data collection and São Paulo Research Foundation (Process 2016/12766-6)

\section{REFERENCES}

1. Glanz K, Sallis JF, Saelens BE, Frank LD. Healthy nutrition environments: concepts and measures. Am J Health Promot. 2005;19(5):330-3, ii. https://doi.org/10.4278/0890-1171-19.5.330

2. Glanz K, Johnson L, Yaroch AL, Phillips M, Ayala GX, Davis EL. Measures of retail food store environments and sales: review and implications for healthy eating initiatives. J Nutr Educ Behav. 2016;48(4):280-288.e1. https://doi.org/10.1016/j.jneb.2016.02.003

3. Rose D, Hutchinson PL, Bodor JN, Swalm CM, Farley TA, Cohen DA, et al. Neighborhood food environments and body mass index. Am J Prev Med. 2009;37(3):214-9. https://doi.org/10.1016/j.amepre.2009.04.024

4. Egger G, Swinburn B. An "ecological" approach to the obesity pandemic. BMJ. 1997;315(7106):477-80. https://doi.org/10.1136/bmj.315.7106.477

5. Swinburn B, Egger G. Preventive strategies against weight gain and obesity. Obes Rev. 2002;3(4):289-301. https://doi.org/10.1046/j.1467-789X.2002.00082.x

6. Jaime PC, Duran AC, Sarti FM, Lock K. Investigating environmental determinants of diet, physical activity, and overweight among adults in Sao Paulo, Brazil. J Urban Health. 2011;88(3):567-81. https://doi.org/10.1007/s11524-010-9537-2

7. Ministério da Saúde (BR), Secretaria de Vigilância em Saúde, Departamento de Análise de Situação de Saúde. Plano de Ações Estratégicas para o Enfrentamento das Doenças Crônicas Não Transmissíveis (DCNT) no Brasil 2011-2022. Brasília, DF; 2011 [cited 2019 Mar 22]. Available from: http://bvsms.saude.gov.br/bvs/publicacoes/plano_acoes_enfrent_dcnt_2011.pdf

8. Glanz K, Sallis JF, Saelens BE, Frank LD. Healthy nutrition environments: concepts and measures. Am J Health Promot. 2005;19(5):330-3, ii. https://doi.org/10.4278/0890-1171-19.5.330

9. Almeida LB, Scagliusi FB, Duran AC, Jaime PC. Barriers to and facilitators of ultra-processed food consumption: perceptions of Brazilian adults. Public Health Nutr. 2018;21(1):68-76. https://doi.org/10.1017/S1368980017001665

10. Ravensbergen EAH, Waterlander WE, Kroeze W, Steenhuis IHM. Healthy or unhealthy on sale? A cross-sectional study on the proportion of healthy and unhealthy foods promoted through flyer advertising by supermarkets in the Netherlands. BMC Public Health. 2015;15:470. https://doi.org/10.1186/s12889-015-1748-8

11. INFORMAS. Country Matrix updated March 2019. Aukland (NZL): University of Aukland; 2019 [cited 2019 Mar 22]. Available from: https://www.informas.org/country-matrix-2/

12. Ministério da Saúde (BR), Secretaria de Atenção à Saúde, Departamento de Atenção Básica. Guia alimentar para a população brasileira. 2 ed. Brasília, DF; 2014 [cited 2019 Mar 22]. Available from: http://bvsms.saude.gov.br/bvs/publicacoes/guia_alimentar_populacao_ brasileira_2ed.pdf

13. Ministério da Saúde. Política Nacional de Alimentação e Nutrição (PNAN). Brasília, DF; 2013 [cited 2019 Mar 22]. Available from: http://bvsms.saude.gov.br/bvs/publicacoes/politica_ nacional_alimentacao_nutricao.pdf

14. Glanz K, Sallis JF, Saelens BE, Frank LD. Nutrition Environment Measures Survey in stores (NEMS-S): development and evaluation. Am J Prev Med. 2007;32(4):282-9. https://doi.org/10.1016/j.amepre.2006.12.019

15. Martins PA, Cremm EC, Leite FHM, Maron LR, Scagliusi FB, Oliveira MA. Validation of an adapted version of the nutrition environment measurement tool for stores (NEMS-S) in an urban area of Brazil. J Nutr Educ Behav. 2013;45(6):785-92. https://doi.org/10.1016/j.jneb.2013.02.010

16. Duran AC, Lock K, Latorre MRDO, Jaime PC. Evaluating the use of in-store measures in retail food stores and restaurants in Brazil. Rev Saude Publica. 2015;49:80. https://doi.org/10.1590/S0034-8910.2015049005420

17. Monteiro CA, Cannon G, Moubarac JC, Levy RB, Louzada MLC, Jaime PC. The UN Decade of Nutrition, the NOVA food classification and the trouble with ultra-processing. Public Health Nutr. 2018;21(1):5-17. https://doi.org/10.1017/S1368980017000234 
18. Monteiro C, Cannon G, Levy R, Moubarac J, Jaime P, Martins A, et al. NOVA. The star shines bright. Food classification. Public Health. World Nutr. 2016;7(1-3):28-38.

19. Monteiro CA, Cannon G, Levy RB, Moubarac JC, Louzada ML, Rauber F, et al. Ultra-processed foods: what they are and how to identify them. Public Health Nutr. 2019;22(5):936-41. https://doi.org/10.1017/S1368980018003762.

20. Ohri-Vachaspati P, Leviton LC. Measuring food environments: a guide to available instruments. Am J Health Promot. 2010;24(6):410-26. https://doi.org/10.4278/ajhp.080909-LIT-190

21. Instituto Brasileiro de Geografia e Estatística. Pesquisa de Orçamentos Familiares, 2008-2009: análise do consumo alimentar pessoal no Brasil. Rio de Janeiro: IBGE; 2011.

22. Rubio DM, Berg-Weger M, Tebb SS, Lee ES, Rauch S. Objectifying content validity: conducting a content validity study in social work research. Soc Work Res. 2003;27(2):94-104. https://doi.org/10.1093/swr/27.2.94

23. Durán AC, Almeida SL, Latorre MRDO, Jaime PC. The role of the local retail food environment in fruit, vegetable and sugar-sweetened beverage consumption in Brazil. Public Health Nutr. 2016;19(6):1093-102. https://10.1017/S1368980015001524

24. Costa JC, Claro RM, Martins APB, Levy RB. Food purchasing sites. Repercussions for healthy eating. Appetite. 2013;70:99-103. https://doi.org/10.1016/j.appet.2013.06.094

25. Landis JR, Koch GG. The measurement of observer agreement for categorical data. Biometrics. 1977;33(1):159-74.

26. Rousson V, Gasser T, Seifert B. Assessing intrarater, interrater and test-retest reliability of continuous measurements. Stat Med. 2002;21(22):3431-46. https://doi.org/10.1002/sim.1253

27. Duran AC, Almeida SL, Latorre MRDO, Jaime PC. The role of the local retail food environment in fruit, vegetable and sugar-sweetened beverage consumption in Brazil. Public Health Nutr. 2016;19(6):1093-102. https://doi.org/10.1017/S1368980015001524

28. World Health Organization. Marketing food to children: changes in the global regulatory environment, 2004-2006. Geneva: WHO; 2007 [cited 2018 Oct 10]. Available from: http://www.who.int/dietphysicalactivity/publications/regulatory_environment_2007/en/

29. Nau C, Kumanyika S, Gittelsohn J, Adam A, Wong MS, Mui Y, et al. Identifying financially sustainable pricing interventions to promote healthier beverage purchases in small neighborhood stores. Prev Chronic Dis. 2018;15:E12. https://doi.org/10.5888/pcd15.160611

30. Rimkus L, Isgor Z, Ohri-Vachaspati P, Zenk SN, Powell LM, Barker DC, et al. Disparities in the availability and price of low-fat and higher-fat milk in US food stores by community characteristics. J Acad Nutr Diet. 2015;115(12):1975-85. https://doi.org/10.1016/j.jand.2015.04.002

31. Claro RM, Monteiro CA. Family income, food prices, and household purchases of fruits and vegetables in Brazil. Rev Saude Publica. 2010;44(6):1014-20. https://doi.org/10.1590/S0034-89102010000600005

Funding: Financial support for data collection from the International Development Research Center (IDRC) and Brazilian Institute of Consumer Protection (IDEC). Funding agency of the project: Fundação de Amparo à Pesquisa do Estado de São Paulo (Process 2016/12766-6).

Authors' Contribution: Study design and planning, data analysis and interpretation, manuscript preparation: $\mathrm{CAB}$. Result interpretation and manuscript review: PCJ. Approval of the final version and public responsibility for the article: $\mathrm{CAB}, \mathrm{PCJ}$.

Conflict of interest: The authors declare no conflicts of interest. 